Daniela Marčok

Univerzitet u Novom Sadu

Filozofski fakultet

Odsek za slovakistiku

danielamarcokova@ff.uns.ac.rs
УДК 811.162.4:371(497.113)"18"

https://doi.org/10.18485/slavistika.2021.25.2.15

Стручни рад

примљено 2.3.2021.

прихваћено за штампу 6.10.2021.

\title{
SLOVAČKE EVANGELISTIČKE ŠKOLE U BAČKOJ U ZAPISNICIMA KANONSKIH VIZITACIJA IZ 1835. GODINE*
}

Ubrzo nakon doseljavanja velikog broja Slovaka iz Gornje i Srednje u Donju / Južnu Ugarsku krajem 18. veka stanovništvo nekatoličke vere je Patentom o toleranciji steklo pravo na osnivanje svojih crkava i škola pod svojim okriljem. Kanonska vizitacija - zvanična poseta superintendanta (kasnije biskupa, najvišeg crkvenog velikodostojnika evangelističke crkvene oblasti) crkvenim zajednicama na teritoriji svoje superintendanture, podrazumevala je kontrolu rada tih crkvenih zajednica uz obavezno vođenje zapisnika. Ovi zapisnici nude prvorazredne autentične podatke o stanju crkvenih objekata, inventaru, o odnosima u parohiji, stanovništvu i vernicima, o samom svešteniku, o groblju, o crkvenim obredima, kao i o školama i učiteljima itd. Predmet ovog istraživanja bili su oni delovi kanonskih vizitacija slovačkih evangelističkih crkvenih zajednica u Bačkoj (Bajša, Gložan, Kulpin, Kisač, Lalić, Petrovac, Pivnice, Selenča), koji se odnose na školu. Detaljnom analizom zapisnika kanonskih vizitacija došlo se do novih, do sada nepoznatih podataka o učiteljima, uslovima rada i funkcionisanju slovačkih evangelističkih škola u Bačkoj u prvoj polovini 19. veka.

Ključne reči: slovačke evangelističke škole, Bačko-sremski seniorat, kanonska vizitacija iz 1835. g.

Shortly after the immigration of a large number of Slovaks from Upper and Middle to Lower / Southern Hungary in the late $18^{\text {th }}$ century, thanks to the Patent on Tolerance, the population of the non-Catholic denomination acquired the right to establish their own churches and schools under their auspices. The canonical visitation - the official visit of the superior (later the bishop, the highest ecclesiastical dignitary of the Evangelical Church area) to the church communities on the territory of his jurisdiction, implied control over the work of those church communities with obligatory record keeping. These records offer first-rate authentic data on the condition of church buildings, inventory, relations in the parish, population and believers, about the priest himself, the cemetery, church holidays, as well as schools and teachers, etc. This research focused on those parts of the canonical visitations of Slovak Evangelical Church communities in Bačka (Bajša, Gložan, Kulpin, Kisač, Lalić, Petrovac, Pivnice, Selenča) which refer to the school. Through a detailed analysis of the records of canonical visitations, we uncovered new, yet unknown data on the teachers, working conditions and the functioning of Slovak Evangelical schools in Bačka in the first half of the $19^{\text {th }}$ century.

Keywords: Slovak evangelical schools, Bačka-Srem seniorate, canonical visitation from 1835.

U 16. veku je u Evropi nastao veliki duhovni, crkveni i kulturni pokret protiv papstva i rimokatoličke crkve poznat kao protestantska reformacija. Pristalice reformacije proglasile su Sveto pismo jedinim izvorom vere, zalagale su se za život u skladu sa Hristovim učenjem koji će omogućiti povratak starim vrednostima, tj. principima

* Rad je nastao u okviru projekta Diskursi manjinskih jezika, književnosti i kultura ujugoistočnoj i srednjoj Evropi (178017), koji finansira Ministarstvo prosvete, nauke i tehnološkog razvoja Republike Srbije. 
prvobitnog hrišćanstva. Nemački reformator dr Martin Luter (Martin Luther) objavio je 1517. godine na crkvi zamka u Vitenbergu (Wittenberg) 95 teza kojima je pozvao predstavnike rimokatoličke crkve na diskusiju o nekim crkvenim pitanjima, posebno o prodaji indulgencija vernicima. Odbio je da prihvati primat pape u hrišćanskom svetu i javno je spalio papsku bulu, čime je rascep sa Vatikanom bio potpun. Širenju reformacije u Ugarskoj na teritoriji Slovačke doprineli su studenti koji su odlazili na studije u Vitenberg i koji su kući donosili reformacione ideje i Luterove spise. Evangelistička crkva augzburške veroispovesti (dalje: evangelistička crkva a. v.) dobila je ime po gradu Augzburgu (Augsburg), gde je 1530. godine prvi put javno pročitan sadržaj evangelističke veroispovesti pred carem Karlom V. Velika većina nemačkih i slovačkih crkvenih zajednica se priklonila augzburškoj veroispovesti, čime su postavljeni temelji zajedničke evangelističke crkve a. v.

Karlo III je izdao 1731. godine prvi dekret (Caroline resolutio I) kojim se uređuju (ograničavajuća) prava protestanata u Ugarskoj. Druga Karlova rezolucija iz 1734. godine dozvoljava protestantima teritorijalnu podelu na četiri distrikta koji biraju vlastitog superintendanta, najvišeg crkvenog velikodostojnika. Funkcija superintendanta bila je počasna, bez ikakvih ovlašćenja i novčane nadoknade. Banski distrikt, jedan od četiri teritorijalno-upravna dela evangelističke crkve u Ugarskoj, bio je podeljen na seniorate, a jedan od njih je bio Bačko-sremski seniorat (Petrík, Rybár 2001: 158, 28). ${ }^{1}$

Stanovništvu evangelističke vere u Ugarskoj je tek nakon objavljivanja Patenta o toleranciji 1781. godine bilo dozvoljeno osnivanje crkava, parohija i škola, a ugarski sabor je 1791. godine XXVI članom zakona obezbedio evangelicima potpunu versku slobodu i školsku autonomiju (Petrík, Rybár 2001: 365). Slovaci, koji su se krajem 18. veka masovno doseljavali u Donju Ugarsku, u nedostatku vlastitih intelektualaca u svoje škole pozivali sveštenike i učitelje iz Gornje Ugarske. Ove škole su pripadale crkvi sve do njihovog podržavljenja nakon Prvog svetskog rata.

Prve kanonske vizitacije slovačkih evangelističkih crkvenih zajednica na teritoriji Bačke i Srema bile su održane 1798, 1810. i 1825. godine.

Pre početka kanonske vizitacije evangelističkih crkvenih zajednica Bačkosremskog seniorata 1835. g. (a Banatskog 1836. g.) svaka crkvena zajednica je od crkvenih vlasti dobila uniformna pitanja na latinskom jeziku na koja je mesni sveštenik odgovarao u pismenoj formi. ${ }^{2}$ Komisija kanonske vizitacije na čelu sa superintendantom dolazeći u svaku crkvenu zajednicu kontrolisala je odgovore

${ }^{1}$ Postojeći distrikti (Preddunavski, Potiski, Banski i Zadunavski) podeljeni su na seniorate. Do 1894. godine seniorati Banskog distrikta bili su: Zvolenski (Zvolenský), Novohradski (Novohradský), Honćjanski (Hontiansky), Tekovski (Tekovský), Peštanski (Peštiansky), Bačko-sremski (Báčsko-sriemsky), Bekeški (Békešský), Banatski (Banátsky), Aradski (Aradský), Torontalski (Torontálsky), i Temeški (Temešský). Nakon budimpeštanske sinode 1894. godine promenila se teritorijalna raspodela seniorata, a Banski distrikt kao takav postojao je do 1918. godine (Petrík, Rybár 2001: 28).

2 Prepis uniformnih pitanja (Schema Visitationis Canonicae anno 1835 per Inclytum at Venerabilem Senioratum Bács-Sirmiensem instituendae) za ovu kanonsku vizitaciju sačuvan je u knjizi protokola intimata i cirkulara u Centralnom arhivu SEAVC u Srbiji u Staroj Pazovi (Protocollum Intimatorum et Currentalium Ecclesiae A. C. Addictorum Vetero-Pazoviensis in Sirmio ab anno 1826. Volumen VIII). 
sveštenika i faktičko stanje na licu mesta, a u zapisnik je unosila mišljenje o moralnom karakteru sveštenika, napomene ili eventualne obavezujuće preporuke sa ciljem otklanjanja uočenih nedostataka.

Predmet ovog istraživanja su delovi zapisnika kanonskih vizitacija slovačkih evangelističkih crkvenih zajednica u Bačkoj ${ }^{3}$ koji se odnose na školu. U zapisnicima kanonskih vizitacija je ovaj deo označen rimskim brojem V. Iako su poslata uniformna pitanja, u formulisanju odgovora među zapisnicima postoje izvesne formalne razlike. Tako zapisnik kanonske vizitacije u Kulpinu ima potrebnu formu i strukturu, ali nema tražene delove označene rimskim brojevima.

Kanonsku vizitaciju vršio je superintendant Banskog distrikta Jan Seberinji ${ }^{4}$ u sledećim evangelističkim slovačkim crkvenim zajednicama Bačko-sremskog seniorata: Bajša (Bajsa) $)^{5}$, Gložan (Glozsán), Kisač (Kiszács), Kulpin (Kölpény), Lalić (Lality), Petrovac (Petróc), Pivnice (Pivnicza) i Selenča (Bácsújfalu). Stalni članovi komisije u Bačkoj bili su, pored superintendanta J. Seberinjija, bačko-sremski senior Jan Stjehlo, ${ }^{6}$ kapelan Ljudovit Muskuli (Ludovít Muskuly), kraljevski kameralni revizor Fridrih Koroš (Fridrich Koroš) i senioralni zapisničar Jan Škulteti (Ján Škultéty). Broj i sastav komisije u određenoj crkvenoj zajednici bio je promenljiv, jer su u pojedinim komisijama vizitacije učestvovali i sveštenici iz drugih slovačkih evangelističkih crkvenih zajednica u Bačkoj, kao i predstavnici lokalnih vlasti.

U svim slovačkim evangelističkim crkvenim zajednicama su postojale konfesionalne škole na slovačkom jeziku. Svaka crkvena zajednica je pozivala, primala i potpisivala ugovor (vocator) sa sveštenikom i učiteljem o njihovom izdržavanju. U zapisniku se, u delu koji se odnosi na školu, najpre navode biografije tadašnjih mesnih učitelja, a ponegde i njihovih prethodnika sa ponekim kratkim komentarom o njihovim moralnim i stručnim karakteristikama koje daje mesni sveštenik. Iz zapisnika se može zaključiti da su učitelji mahom dolazili iz Gornje Ugarske, gde su većinom i završavali škole, ali je bilo i izuzetaka.

U Bajši je u vreme kanonske vizitacije učitelj bio Daniel Martinek koji je završio pravoslavnu gimnaziju u Novom Sadu sve do retorike, a u Šemnjici (Banska Śtjavnjica) završio je filozofiju i teologiju. ${ }^{7}$ Navodi se da je obrazovan, dobrog ponašanja, učiteljsku dužnost savesno obavlja. Međutim, mesni sveštenik primećuje da roditelji nemarno posećuju crkvu, a svoje neodgovorno ponašanje pokazuju i prema školi, pošto neredovno šalju svoju decu na nastavu. Pravdaju to siromaštvom i nedostatkom odeće za decu u zimskom periodu. U toplijem delu godine glavni

${ }^{3}$ Protocolla Visitationis Ecclesiarum Eglican A. C. Bacs-Sirmiesnium, institutae anno 1835. mensibus Septembri et Octobri (Protokoli kanonskih vizitacija evangelističkih a. v. crkvenih zajednica Bačko-sremskog seniorata održanih u septembru i oktobru 1835. godine).

${ }^{4}$ Jan Seberinji (slov. Ján Seberini, mađ. Jan Szeberényi, 1780-1857), konsenior, senior, superintendant Banskog distrikta u Bačko-sremskom senioratu od 1834-1850. g.; pedagog, polihistor (Petrík, Rybár 2001: 28, 314).

${ }^{5}$ U zagradi je naziv mesta naveden tako, kao što se navodi u Protokolu kanonskih vizitacija.

${ }^{6}$ Jan Stjehlo (Ján Stehlo, 1787-1868), sveštenik, senior, osnivač Nedeljne škole u Bačkom Petrovcu. Zaštitinik slovačke crkve protiv mađarizacije u Donjoj Ugarskoj (Petrík, Rybár 2001: 350).

${ }^{7}$ Segi navodi da je Daniel Martinek završio Banskošćjavnički evangelistički licej 1830. godine (Сеги 2020: 524). 
razlog nedolaska dece u školu su poljoprivredni radovi koji intenzivno traju od proleća pa sve do polovine novembra, a roditelji u sve poslove uključuju i svoju decu. Škola nije imala fondaciju. Završni ispiti su se obavljali u prisustvu roditelja pre početka prolećne poljoprivredne sezone. Učenici nisu imali udžbenike. Dekan je učitelju davao instrukcije (preporučivao ,seriju lekcija” tj. nastavno gradivo). Mesni sveštenik navodi da u svojstvu inspektora često posećuje školu, podržava učitelja u obavljanju dužnosti i usmerava njegov rad u korist blagostanja zajednice. ${ }^{8}$

U Gložanu je učitelj, istovremeno i kantor, Juraj Rohonj (Juraj Rohoň). Sveštenik navodi da je učitelj dobro pripremljen za posao koji obavlja, moralan, blag, vredan, razborit, uvek poslušan svešteniku. ${ }^{9}$ Školska zgrada je u lošem stanju, a učionica bez nastavnih sredstava. Škola nema nikakvih fondova. U odeljku „Primedbe i žalbe” zapisnika ove kanonske vizitacije navodi se veliko nezadovoljstvo crkvene zajednice sa sveštenikom i učiteljem, koji uprkos opominjanju viđenijih ljudi iz sela neadekvatno raspolažu crkvenim novcem i nesavesno obavljaju svoje dužnosti. Komisija kanonske vizitacije nalaže učitelju da vredno obavlja svoje dužnosti, redovno i neprekidno drži nastavu od prvog septembra do poslednjeg dana juna kada treba da održi ispit. Iako učitelja karakteriše kao nemarnog i nezainteresovanog za obavljanje dužnosti, smatra da vaspitna i obrazovna zapuštenost dece (posebno u religiji) nije isključivo njegova greška, već opominje i roditelje da odgovornije šalju svoju decu u školu. Ipak, pošto je on sam već najavio svoj odlazak, savetovano mu je da ,mesto učitelja što pre ostavi dostojnijem i boljem", da bi crkvena zajednica odmah mogla posredstvom seniorata da pozove novog učitelja na upražnjeno mesto. ${ }^{10}$

U Kisaču je u vreme kanonske vizitacije bio učitelj Samuel Mihalovič (Samuel Michalovič), mladić od 21 godine koji je tek dva meseca obavljao službu u Kisaču. Pre toga je tri meseca službovao u Palanci, a zatim dve godine u Kulpinu. ${ }^{11}$ Školovao se u Novom Vrbasu i Mezoberenju (Mezőberény). U zapisniku se navodi da ima lepe manire i da je poslušan prema svešteniku. Za ovo kratko vreme je organizovao prvi dečiji hor, što se smatralo velikim uspehom u učenju, a time je pobrao i simpatije

${ }^{8}$ Slovaci su u Bajši osnovali školu 1764. godine, a tek 1767. godine su dobili prvog učitelja. Iako je bio katoličke veroispovesti, slovački evangelici su Jozefa Namestovskog (Jozef Námestovský) prihvatili za svog učitelja (Sklabinská, Mosnáková 2012: 77).

${ }^{9}$ Evangelistički sveštenik u Gložanu je bio njegov rođeni brat Jan, stoga se ovaj opis učitelja može smatrati subjektivnim. Jan je od 1822. godine bio sveštenik u Kulpinu, ali je nakon smrti svoga oca 1831. godine bio premešten u Gložan. Uprkos solidnom obrazovanju (završio je Gramatičku školu u Novom Vrbasu, arhiepiskopalnu humanioru i gimnaziju u Sremskim Karlovcima i filozofsko-teološke studije u Bratislavi; govorio je slovački, latinski, nemački, mađarski i srpski) superintendant njegov moralni karakter opisuje na ekspresivan način: „,dostojnog oca nedostojan sin; čovek licemeran, pastir koji dobro šiša svoje ovce", navodeći da je isti u konfliktu sa crkvenom zajednicom.

${ }^{10}$ Prvi (neškolovan) učitelj u Gložanu bio je Jozef Sloboda (1770-1785), ratar. Nastava se odvijala najpre u njegovoj kući, kasnije u molitvenom domu, a škola je izgrađena 1802. godine (Miškovic 1986: 195).

${ }^{11}$ Za vreme njegovog službovanja u Kulpinu sam dekan je poklanjao značajnu pažnju školi i mladom učitelju koji je i sam bio posvećen učiteljskom pozivu. Može se pretpostaviti da je razlog prelaska u školu u Kisač bio finansijske prirode, pošto je u Kulpinu bio obavezan da trećinu svojih primanja daje teško bolesnom učitelju Janu Blaziju (Ján Blázi). U školi u Kisaču je radio do svoje smrti 1849. godine (Čelovský 1996: 79-81). 
vernika. O zavidnoj pismenosti svedoči tvrdnja da su osim malobrojnih starijih osoba svi ostali vernici pismeni i koriste crkvenu literaturu i knjige. Roditelji svoju decu rado šalju u školu, kako to zakon nalaže, do njihove 12. godine života. Preporučuje se rad prema Bel Lankasterovoj metodi ${ }^{12}$ kako bi se broj učenika povećao. Vernici rado kupuju crkvene knjige i udžbenike, a dokaz tome je i činjenica da je od 100 pristiglih primeraka Čitanke autora Jana Kolara ${ }^{13}$ za kratko vreme prodato već 40 primeraka. Mesni sveštenik Juraj Jesenski (Juraj Jesenský) u svojstvu inspektora često i bez najave posećuje školu, podstiče učitelja i daje mu dobronamerne savete. Prošle školske godine bilo je 257 upisanih učenika. Školska godina počinje 1. septembra, a završava se u junu. Škola ima iste fondacije kao i crkva. Dekan predlaže i određuje nastavno gradivo. Komisija kanonske vizitacije tj. superintendant dao je primedbu na zanemarivanje učenja hrišćanske veronauke.

U Kulpinu je škola počela da radi oko 1789. godine, a prvi učitelj je bio Jan Lisi (Ján Lisý), koji je posle nekoliko godina otišao u Srem iz privatnih razloga. Na njegovo mesto je došao Juraj Rohonj (Juraj Rohoň), koji je tu predano radio osam godina, a onda je izabran za sveštenika u Gložanu. Na učiteljskoj dužnosti ga nasleđuje Juraj Drotner (Juraj Drottner), ${ }^{14}$ koji je posle izvesnog vremena otišao u Krupinu. ${ }^{15}$ Kada su sledećeg učitelja Paluša ${ }^{16}$ pozvali u Bajšu, na mesto učitelja dolazi Juraj Turčanji (Juraj Turčáni). Dotadašnji učitelj Senioralne škole u Vrbasu Jan Blazi (Ján Blázi) ${ }^{17}$ došao je u Kulpin 1812. godine i bio pod nadzorom sveštenika iz Petrovca sve do 1818. godine. Tada je ovu crkvenu zajednicu vizitirao superintendant Adam Lovič i podržao je Kulpinčane da imaju svog sveštenika. U tom periodu je vlastelin Stratimirović ${ }^{18}$ dodelio evangelističkoj a. v. crkvenoj zajednici jednu i po sesiju zemlje i intravilan (kuću sa dvorištem i baštom) za sveštenika i učitelja. ${ }^{19}$

${ }^{12}$ Ova organizaciona forma učenja nastala je krajem 18. veka kada su nezavisno jedan od drugog anglikanski sveštenik Endrju Bel (Andrew Bell, 1773-1832) i učitelj Džozef Lankaster (Josef Lancaster, 1771-1838) počeli 1798. godine u svom radu da u nastavu uključuju i starije učenike, tako što su pomagali učitelju u podučavanju mlađih učenika (Potkonjak, Šimleša 1989: 47).

${ }^{13}$ V. Kollár 1825.

${ }^{14}$ Prema Čelovskom, ime Štefana Drotnera se pogrešno navodi kao Juraj (Čelovský 1996: 68).

${ }^{15}$ Krupina (mađ. Korpona, nem. Karpfen) - grad u Slovačkoj koji se nalazi u Banskobistričkom kraju.

${ }^{16}$ Georgije Paljuš - Vladar (Juraj Pal’uš - Vladár) (Čelovský 1996: 68).

${ }^{17}$ Opširnije: Čelovský 1996.

18 Porodica Stratimirović je za ratne zasluge dobila posed od carice Marije Terezije 1745. godine, kada počinje i intenzivno doseljavanje Slovaka u Kulpin. Porodica Stratimirović, poreklom iz Hercegovine, u to vreme bila je jedna od najznačajnijih srpskih porodica u Habsburškoj monarhiji. Poznate ličnosti iz ove porodice su, na primer, mitropolit Stevan Stratimirović (1757-1836) i general Đorđe Stratimirović (1822-1908).

19 Jozef Maljijak navodi da su Kulpinčani zemljište namenjeno za podizanje hrama kupili od veleposednika Radivoja Stratimirovića iz Kulpina, kao i kuću sa intravilanom br. 222. Uroš Stratimirović nasilno ju je otuđio od crkve i na taj način osiromašio imovinsko stanje, što je negativno uticalo i na moralno-religijski status crkvene zajednice. Sudski proces je trajao četvrt veka, a već ruinirana kuća je napokon pripala crkvi (Maliak 2000: 5). Čelovski precizira da se radilo o dvorcu sa zemljištem koje su kulpinski Slovaci kupili tek 1846. godine, a Uroš Stratimirović se tog poseda domogao prevarom i tako sprečio izgradnju crkve i novih školskih zgrada. Osim mate- 
Sveštenik Jan Rohonji, koji je po pozivu došao iz Banske Bistrice (Banská Bystrica) 1821. godine, često posećuje školu i polaže velike nade u novopostavljenog učitelja koji rado prima njegove savete. Dekan svečano dolazi na prolećne ispite i mada propisuje nastavno gradivo, školu nikad ne posećuje. Vernici šalju decu u školu u velikom broju, ali je dosta i onih koji ne dolaze.

U Laliću je prvi učitelj od 1791. do1798. godine bio Jan Kramar (Ján Kramár) poreklom iz sela Štjavnjička (Štiavnička) u županiji Turoc. Posle njega je došao Samuel Greškovič koji je umro već sledeće 1799. godine. Slovaci iz Lalića su 1800. godine pozvali Samuela Jesenskog iz Turocke Doline, koji je sedamnaest godina obavljao dužnost učitelja, a 1817. godine je primio svešteničko posvećenje. Te godine crkva je postala majka (parohija), a crkvena zajednica Selenča joj je priključena kao ćerka (filijala). Od tada je učitelj bio Peter Triznaj. Posle njega je 1830. godine za učitelja u Lalić došao Jozef Godra. Učiteljsku dužnost obavljao je marljivo, učio je decu crkvenom pevanju, bio je častan i vredan, posvećen religiji i poslušan svešteniku. U školi je 1834. godine bilo 132 đaka koji su školu marljivo pohađali od prvog septembra do prvog aprila. U zapisniku kanonske vizitacije nema pritužbi na učitelja i njegov rad od strane crkvene opštine, niti pritužbi učitelja protiv opštine ili sveštenika.

U vreme kanonske vizitacije škola u Petrovcu je imala dva odeljenja i dva učitelja. Učitelj škole za dečake je od 1821. godine bio Benjamin Rajs (Benjamin Reisz) poreklom iz Zoljo-Liptova ${ }^{20}$ u Zvolenskoj županiji. Posle završene trivijalne škole pohađao je gramatičku školu u Tisovcu (Tisovec) i Banskoj Bistrici. Nakon završetka ove škole 1813. godine tri godine je nastavio školovanje u Prešovu, posle toga u Mezoberenju odakle je 1819. godine bio pozvan u Bajšu na mesto učitelja. Ovde je radio dve godine, a 1821. godine otišao je u školu u Petrovac. Prečasni Adam Lovič ga je ispitao iz teologije i dozvolio mu je da u slučaju potrebe, kao levita, može obaviti svetu propoved, krstiti i uvoditi porodilju u hram. Dodeljen mu je stepen levite. U zapisniku se navodi da je njegov moralni lik za pohvalu. Obaveze uspešno obavlja kako u školi tako i u crkvi. Prošle, 1834. godine, u školi je imao 322 dečaka. Učitelj u školi za devojčice bio je Ludovik Zvarinji, poreklom iz sela Irša (Albertirsa) u Peštanskoj županiji. Njegov otac Mihal je bio sveštenik. Ludovik je upisao Gramatičku školu u Banskoj Bistrici 1820. godine, odakle je 1822. godine otišao u Šemnicu gde je do 1831. godine završio sve razrede. Tada je pozvan za učitelja u Petrovac. Navodi se da je lepog ponašanja i da svoje dužnosti u školi i crkvi obavlja za pohvalu. U školi je 1834. godine imao 274 devojčice. Oba učitelja izvode nastavu prema instrukciji, uputstvu i propisanim lekcijama od seniorata. Nastava u školi traje od septembra do jula. Školska zgrada je sagrađena pored crkve 1825 . godine. Od čvrstog je materijala, pokrivena šindrom, 32 hvata dužine i 5 hvati širine. Ima dve učionice i stanove za dva učitelja. Svaki stan ima po tri sobe, predsoblje i špajz. Inspektor škole je lokalni sveštenik Jan Sćehlo. Mnogi roditelji decu šalju u školu samo zimi, dok u proleće ili leto školska deca ostaju kod kuće da čuvaju

rijalne štete sudski proces je imao deprimirajući uticaj na kulpinske Slovake. Škole i stanovi za učitelje su izgrađeni tek 1899. godine (Čelovský 1996: 93).

${ }^{20}$ Zolyo-Lipcse (Zvolenská L’upča). Danas: Slovačka Ljupča (Slovenská L’upča), mesto u Slovačkoj u Banskobistričkom kraju. 
mlađu decu ili zbog pomaganja oko poljoprivrednih radova. Ispiti kojima predsedava dekan drže se krajem marta ili u aprilu, uz prisustvo sveštenika iz susednih slovačkih sela, učitelja i vernika. Skoro svi vernici znaju da čitaju i pišu. Zapisniku kanonske vizatacije priložen je ugovor sa učiteljem Rajsom iz 1832. godine. Istovetan ugovor potpisan je i sa učiteljem Ludovikom Zvarinjijem 10. augusta 1835. godine. ${ }^{21}$

Evangelistička a. v. crkvena opština u Pivnicama je osnovana kao slovačkomađarska 1790. godine. Slovačka crkvena opština se osamostalila 1792. godine kada je za učitelja i levitu doveden Andrej Liptaj koji je 1796. godine postao sveštenik, a Andrej Ruman je izabran za kantora. Krajem 1796. godine, 10. oktobra dovode za učitelja Juraja Turčana, koji je u junu 1797. godine prešao u Kulpin, a učiteljsku dužnost je u julu te godine preuzeo Gašpar Leporis (Gašpar Lepóris). Posle njegovog otpuštanja 1803. godine učiteljsku dužnost je preuzeo Martin Javorski (Martin Javorský) i časno je obavljao do svoje smrti 1808. godine. Zatim je za učitelja pozvan Ladislav Varadi iz županije Šimeg koji je učiteljsku dužnost obavljao od 24. aprila 1809.do 1812. godine. Dana 12. septembra 1812. godine je za učitelja pozvan Juraj Turčanji (Juraj Turčáni) koji je u martu 1825. godine bio otpušten, a dužnost učitelja je 1826. godine preuzeo Jan Tihonj (Ján Tychoň), učitelj iz filijale Palanka. Bio je poreklom iz sela Hlboke (Hlboké) u Njitrijanskoj županiji. Prvo je pohađao latinsku školu u Sakolju, ${ }^{22}$ a posle završetka humaniore služio je u Modri23 i Papi ${ }^{24}$ kao pisar kod lokalnog išpana Aleksandra Dulickog. Prošle, 1834. godine, bilo je 242 učenika koji su školu redovno pohađali samo zimi. Nastava je trajala od 1. oktobra do kraja aprila, a održavala se i pre i posle podne. Ispit se obično držao oko Uskrsa. Školska zgrada je nova, stan za učitelja još nije adaptiran. Učionica je prostrana, ali u njoj nema nikakvih nastavnih sredstava. Škola nema fondove. Inspektor škole je mesni sveštenik. Komisija kanonske vizitacije zahteva od sveštenika i đaka da u katehizaciji koriste slovački jezik, jer postoje i udžbenici na slovačkom jeziku; opominju se vernici i učenici da nastava treba da traje deset meseci, a ne četiri kao do sada; opominje se učitelj da ne iskazuje nepoštovanje i mržnju prema svešteniku i da marljivije obavlja učiteljsku dužnost.

Učitelj škole u Selenči bio je Ignac Ručka (Ignác Rúčka). ${ }^{25}$ Škole je završio u Asodu (Aszód), Pešti i Mezoberenju odakle je najpre bio pozvan za učitelja u Piliš, kasnije u Kovačicu i na kraju u Selenču. Sveštenik za njega navodi da mu je moralni

${ }^{21}$ Slovaci evangelici u Petrovcu su se od doseljenja 1745. godine do 1783. godine nalazili pod patronatom rimokatoličke parohije u Futogu (kao i stanovnici Kisača, Kulpina i Gložana koji su se u drugoj polovini 18. veka doseljavali na posed futoškog vlastelinstva). Slovaci u Petrovcu su 1750. godine dobili dozvolu da osim katoličkog učitelja Robotkaja (Robotkay) mogu da imaju i svog evangelističkog kantora, a njegova dužnost je bila da školsku omladinu nedeljom uči evangelističkoj veronauci (Lipták 1995: 653). Marija Terezija je 1779. godine dozvolila pozivanje učitelja evangelističke vere koji bi decu učio čitanju, pisanju, gramatici i katehizmu (AV BBŽ 1779/60). Kantor i prvi učitelj evangelističke crkve u Petrovcu je bio Daniel Zaturecki (Daniel Záturecký) od 1784. godine (Lipták 1995: 654).

${ }^{22}$ Sakolj (Szakoly) je grad u Mađarskoj u županiji Sabolč-Satmar-Bereg.

${ }^{23}$ Modra je grad u Slovačkoj u okviru Bratislavskog kraja.

${ }^{24}$ Papa (mađ. Pápa) je grad u Mađarskoj u županiji Vesprem.

${ }^{25}$ U Selenči je službovao od 1830. do 1867. godine, kada je umro (Šimoni 1998: 577). 
i pedagoški karakter dobar. Njegov privatni život je častan. Uprkos tome što nema najbolja primanja, učiteljsku dužnost vrši primerno, posebno se zalaže u nastavi veronauke gde služi kao primer vlastitom pobožnošću. Takođe uči crkveno pevanje i propoveda. Broj učenika je 164 ali školu pohađaju dosta nemarno. Kao razlozi nesavesnog slanja dece u školu se navode kućni poslovi, slanje dece na služenje, kao i sezonski poljoprivredni radovi. Učenici dolaze u školu od početka oktobra i preko zime, a posle ispita više ne dolaze. Malo je onih koji do 12. godine života pohađaju nastavu. Učitelj ima nekomforan stan, trebalo bi izgraditi novi. Škola nema nikakvih fondova. Sveštenik u svojstvu inspektora posećuje školu dva-tri puta godišnje i propisuje učenicima nastavno gradivo. Komisija kanonske vizitacije nalaže da školska nastava treba bez prekida da traje od 1. septembra do kraja juna.

Iz svega navedenog možemo zaključiti da su uslovi rada bili teški i učitelji su često menjali mesta službovanja, odlazeći u one crkvene zajednice u kojima su im ugovorom ponuđena bolja primanja, pa makar se radilo i o minimalnim razlikama. To, nažalost nije bila nikakva garancija, pošto kod stanovništva još uvek nije bila dovoljno razvijena svest o značaju obrazovanja, tako da su neredovno izmirivali svoje dugove prema školi i učiteljima.

Plata učitelja je bila određena ugovorom, tzv. vokatorom koji je određivala svaka crkvena zajednica, a sastojala se od novčanog dela, proizvoda u naturi i usluga. Kao primer navodimo vokator učitelja slovačke evangelističke crkvene zajednice u Bajši koja je 1835. godine brojala 880 vernika. U Bajši je u gotovom novcu od svakog bračnog para uzimano 18 krajcara. Vernici su obrađivali učiteljevu zemlju - četvrtinu sesije (tj. orali, sejali, žnjeli i dovozili letinu i mleli žitarice samo za njegove lične potrebe). Osim toga, svaki seljak je godišnje davao pola požunske mere očišćene pšenice, a inkvilin četvrtinu mere. Učitelj je dobijao od crkvene zajednice dva hvata drva za ogrev; iz prikupljene „ofere”: za Novu godinu, na Cveti (slov.Kvetná nedel'a) ${ }^{26}$ i na Duhove (slov,Turice). ${ }^{27}$ Od novca prikupljenog za koledu trećina je pripadala učitelju. Imao je prihod i od pravljenja hostija. Od sahrane sa pevanjem dobijao je 18 krajcara, sa oproštajnim govorom jedan floren. Od svakog deteta koje je pohađalo školu dobijao je 15 krajcara, jednog petla i sedam jaja. Od novca koji plaćaju konfirmanti dobija tri florena i za kredu 30 krajcara. Slični ugovori sa učiteljima su bili sačinjeni i u ostalim slovačkim crkvenim evangelističkim zajednicama.

Pored čitanja i pisanja (slovačkog i mađarskog jezika), aritmetike, veronauke, biblijske istorije, istorije prirode, geografije Ugarske, u nekim crkvenim zajednicama se navode i predmeti: istorija reformacije, građansko vaspitanje, dijetetika, istorija Ugarske, horsko pevanje, kaligrafija, a iz fizike se uči „,ono što je bilo primereno intelektualnim mogućnostima učenika da se iskoreni sujeverje naroda". ${ }^{28}$

${ }^{26}$ Cveti su pokretni hrišćanski praznik kojim se obeležava Hristov ulazak u Jerusalim, tj. poslednja nedelja njegovog života. Uvek pada u nedelju, nedelju dana pre Uskrsa.

${ }^{27}$ Duhovi ili Pedesetnica je hrišćanski praznik kojim se obeležava silazak Svetog Duha na apostole u Jerusalimu, 50 dana nakon Hristovog Vaskrsenja.

${ }^{28} \mathrm{Za}$ učitelje evangelističkih škola Bačko-sremskog seniorata su njegovi dekani u dvadesetim godinama 19. veka priredili uputstvo pod nazivom Úprava pre učitelov evanjelických a. v. škôl báčsko-sriemskeho seniorátu. Sada već izgubljeni latinski original je na slovački jezik preveo slovački vojvođanski istoričar Jozef Maliak (1854-1945). U ukupno 24 tačke obrađeni su: način pozivanja 
Osim Kolarove Čitanke u zapisnicima nisu zabeleženi drugi udžbenici za učenike, niti bilo kakva nastavna sredstva. Učitelji su se za nastavu pripremali iz nekih od sledećih knjiga: Herderovog Katehizma, ${ }^{29}$ Luterovog Malog katehizma, Hibnerove Biblijske istorije, ${ }^{30}$ Bartolomeidesove Geografije, ${ }^{31}$ Palkovičove Geografije, ${ }^{32}$ Mihalkove Fizike, ${ }^{33}$ Kolarove Čitanke, Leškovog Katehizma, Jevanđelja Novog zaveta, a učenike su učili ponešto i iz Istorije prirode, Istorije Ugarske, kao i molitvenim i pogrebnim pesmama. ${ }^{34}$

učitelja i njegova primanja, okvirni vaspitno-obrazovni ciljevi, disciplinske mere u slučaju nepoštovanja propisa, ophođenje učitelja prema učenicima itd. Tačka 7 ovog uputstva tiče se konkretnog programa i sadržaja nastave. Preporučuje se da se omladina poučava u svemu što je potrebno za život, a to je: računanje u glavi, krasnopis, nekoliko poglavlja iz prirodopisa, katehizam veronauke, katehizam zdravlja, izbor iz biblijske istorije, zatim geografija, građansko vaspitanje, a iz fizike pre svega o prirodnim pojavama sa cijem sprečavanja sujeverja (Čelovský 1996: 85-86). Očigledno je da su se učitelji pridržavali ovih uputstava, jer se u zapisnicima kanonske vizitacije istovetno navode neke od gorenavedenih formulacija.

${ }^{29}$ Johann Gottfried von Herder (1744-1803, nemački pesnik i pisac, generalni superintendant u Vajmaru (Weimar) (Rizner 1931: 87)). Katechysmus doktora M. Luthera, s obssjrným Katechetyckým Wýkladem Wysoce oswjceného Doktora Jana Gottrieda Herdera, k prospěchu sskol ewangelických z nemeckého od Jana Gryssy, někdegssjho SI. B. K. Pezynského, přeloženým. Wydal na swůg náklad, toto Slowenské přeloženj ponaprawiw, Giřj Palkowič. W Presspurku 1809. Pjsmem Ssimona Petra Webera. Sa velikom verovatnoćom upotrebljavali su četvrto nepromenjeno izdanje koje je bilo štampano u Bratislavi 1825. godine u štampariji „Karla K. Snjžka”. Peto nepromenjeno izdanje je izašlo u Bratislavi 1838. godine „W Prespurku 1838. Pjsmem vrozeného Antonjna Smida a Komp” a šesto „W Presspurku 1840. Pjsmem Belnayho Dedicú” (Rizner 1932a: 121).

${ }^{30}$ Johann Hübner (1668-1731, nemački pedagog). Biblické Hystorye, w Počtu Sto a čtyry, po Padesáte a dwau, gednak ze Starého gednak z Nowého Zákona, wybrané od J. H., Škol Hamburských Rektora, Nyni pak k dobrému Slowenské Mládeže, která se Augsspurského wyznánj př́držj, w domácy Gazyk přetlumočené. W Presspurku a w Pessti 1834. U Ludwjka Landerera, urozeného z Füskutu (Rizner 1931: 155). Ova knjiga je prethodno imala pet izdanja: počevši 1778. godinom, zatim 1792., 1793. i 1813. godinom i završavajući 1832. godinom (Čelovský 1996: 119).

${ }^{31}$ Ladislav Bartholomaeides (1754-1825, evangelistički sveštenik). Geograffia aneb Wypsánj Okrsslku Zemského s ssesti Mappami wlastnj Rukau geho wyrytými. W Baňské Bistřicy 1798. Wytisstěné v Jána Sstefániho (Rizner 1929: 91. Opširnije: Čelovský, 1996: 110).

${ }^{32}$ Juraj Palkovič (1769-1850, profesor češkoslovačkog jezika i književnosti na evangelističkom liceju u Bratislavi). Známost Wlasti. Neywjc pro sskoly Slowenské w Vhřjch sepsal a na swůg náklad wydal J. P. Oddělení Prwnj. Známost’ geografická. W Presspůrku v Symona Petra Webera 1804 (Rizner 1932b: 7).

${ }^{33}$ Pavel Michalko (1752-1825, učitelj u Pilišu). Fizyka, aneb Včenj o Přirozenj (Nature) k prospěchu, gak celého Národu, a pěkného Vměnj žádostiwého sepsané. W Budjne 1819. Wytisstěné Literámi Anny Landererky (Rizner 1932a: 206. Opširnije: Čelovský 1996: 110-111).

${ }^{34}$ Uputstvo za učitelje Úprava pre učitel'ov evanjelických a. v. škôl báčsko - sriemskeho seniorátu nastalo u dvadesetim godinama 19. veka je uz manje korekcije važilo još i u drugoj polovini 19. veka. Dekan Samuel Borovski (1783-1860) često je slao cirkularna pisma, saopštenja i druge materijale školama u svom području u kojima je dodatno objašnjavao pojedine tačke uputstva. Tako je u pismu datiranom 9. novembra 1824. godine predlagao raspored časova tokom dana gde navodi i neke udžbenike: nakon pevanja i molitve obrađuje se biblijska istorija, zatim čitanje i pisanje; posle podne moralne pouke iz knjige Moral in Beispielen, zatim prirodopis prvenstveno o domaćim životinjama, potom nešto iz fizike iz knjige Volkes Naturlehre i iz Mihalkove fizike. Napominjao je da ne treba zanemarivati ni pravila o zdravlju, na primer prema Tablicovom izdanju. Zatim treba 
U svim školama je manje-više osnovni problem bilo neredovno pohađanje nastave, posebno u vreme trajanja prolećnih i jesenjih poljoprivrednih radova. Nesavesno slanje dece u školu roditelji su ponekad pravdali siromaštvom, konkretno nedostatkom odeće za decu u zimskom periodu. Malo je bilo onih koji su do 12. godine pohađali školu. Roditelji su bili opominjani i u crkvi i prilikom kolede ${ }^{35}$ ali bez značajnog efekta.

Školske zgrade su većinom bile u trošnom stanju, sa manjkom inventara i nastavnih sredstava, često nedovoljne da prime svu školsku decu. Vernici su bili voljni da grade škole (npr. u Pivnicama), ali je prikupljanje novaca vernika za adaptiranje stanova učitelja išlo sporo. Stanovi tj. sobe učitelja u većini slučajeva nisu bile komforne, ponegde je tavanica bila od dasaka. Školska zgrada sa stanom učitelja u Kisaču bila je dosta prostrana. U Petrovcu su bili najbolji uslovi: školska zgrada je bila relativno nova, prostrana, sagrađena od čvrstog materijala, pokrivena šindrom. Imala je dve učionice i stanove za dva učitelja. Svaki stan je imao po tri sobe, predsoblje, špajz.

Komisija kanonske vizitacije je verovatno bila svesna teških uslova života i rada i nije beležila mnogo zamerki. U Bajši nalaže učitelju da se ispit drži krajem juna i da do tada deca treba da dolaze u školu. U Kulpinu vernici često zanemaruju pomoć - doprinos za Senioralnu školu u novčanom iznosu od 3 florena, a u naturi 1 peštanski merov pšenice. U Pivnicama se opominje sveštenik i učenici da prilikom katehizacije koriste slovački jezik, pošto koriste i udžbenike na slovačkom jeziku. U nekoliko zapisnika kanonskih vizitacija opominju se i vernici i učenici da nastava treba da traje deset meseci, a ne četiri meseca prema dosadašnjoj praksi. Takođe se opominju učitelji da iskazuju dužno poštovanje prema svešteniku i da marljivije obavljaju učiteljsku dužnost.

U nekim zapisnicima je deo koji se odnosi na napomene i žalbe (označen rimskim brojem X) ostao prazan (Bajša, Petrovac, Selenča, Kisač, Kulpin, Lalić), u Pivnicama je zabeleženo da ima mnogo zamerki vernika, ali ništa konkretno nije navedeno, dok se crkvena zajednica u Gložanu žalila na sveštenika i učitelja, prvenstveno zbog nesavesnog raspolaganja novčanim sredstvima.

Iako to nije bilo zabeleženo u zapisnicima kanonskih vizitacija, očigledno je da odnos učitelja prema radu i njihove moralne karakteristike nisu uvek bili na zadovoljavajućem nivou, pa su se mnogi vernici u ovim slovačkim evangelističkim crkvenim zajednicama usmeno žalili superintendantu. Na to ukazuje superintendant J. Seberinji u svom svečanom govoru u Novom Vrbasu nakon završene kanonske vizitacije u Bačko-sremskom senioratu. ${ }^{36}$ Stoga predlaže da se sastavi priručna

poučavati istoriju i geografiju države, a nakon toga ponovo čitanje, pevanje i računanje (Čelovský 1996: 87). Samuel Borovski je sastavio prvi bukvar za slovačke učeniku u Bačko-sremskom senioratu: Nowý na přirozeném rozwrženj sylláb založený Slabykár /Novi, na prirodnom rasporedu slogova zasnovan bukvar/ (Skalica, 1853).

${ }^{35}$ U periodu od Badnje večeri (Štedrý večer, 24. decembar) do praznika „Tri kralja” (Traja králi / Tri krále, 6. januar) školska deca su obilazila kuće, pevala božićne pesme - kolede i za to dobijala poklone, najčešće novac i kolače. Uobičajena pojava je bila da sa njima ide učitelj koji je imao zadatak da beleži broj ukućana radi crkvene statistike.

${ }^{36}$ Od slovačkih crkvenih zajednica poslednja je bila vizitirana ona u Pivnicama 19. oktobra, dok je 22. oktobra na svečanom skupu u crkvi u Novom Vrbasu zvanično završena kanonska vizitacija u Bačko-sremskom senioratu. Osim nekolicine pripadnika svetovne vlasti prisustvovali su svi sveštenici Bačko-sremskog seniorata izuzev sveštenika iz Selenče, a svakom je bio uručen zapisnik kanonske vizitacije crkvene zajednice u kojoj služi. U Protokolu zapisnika kanonskih vizitacija Bačko-sremskog senio- 
knjiga koja bi sadržala najbitnije smernice u učenju verskih sadržaja kao i u ponašanju učitelja kako bi se sprečilo obezvređivanje učiteljske profesije, škole i crkve. Bačko-sremski senior Jan Stjehlo je na osnovu ovih njegovih instrukcija napisao posebne odredbe koje je 11. novembra 1835. godine poslao svim bačkosremskim evangelističkim školama. On poziva učitelje i dekane da vlastitim ponašanjem budu pozitivan primer vernicima, a prvenstveno svojim učenicima, da bi od njih vremenom mogli postati „dobri i državi korisni stanovnici, pošteni supružnici, savesni roditelji, i uvek dobri i pravedni hrišćani”. Učiteljima su u četiri tačke predočeni zahtevi po kojima se nalaže: 1. da obavezno drže nastavu od 8 do11 časova pre podne, kao i od 13 do16 posle podne; 2 . da ne odlaze u susedna sela bez preke potrebe; 3 . da brinu o svom spoljašnjem izgledu; da budu pristojni u ophođenju sa drugima; da se klone druženja sa seljacima do duboko u noć koja se često završavaju pijanstvima; da ne igraju karte, jer to škodi njihovom ugledu; da ne šetaju ulicom pušeći lulu i da ne ulaze u učionicu sa šeširom ili kapom na glavi; 4. da se niko ne usudi iskorišćavati učenike u domaćim poslovima ili bilo kakvim uslugama, zbog čega su roditelji posebno ogorčeni (Maliak 2000: 7-8). Čelovski naglašava da je tačka 3 najopširnija, što istovremeno ukazuje da je to bio predmet najčešćih žalbi i napomena (Čelovský 1996: 88).

Zapisnici o kanonskim vizitacijama slovačkih evangelističkih crkvenih zajednica u Bačkoj iz 1835. godine kao primarni izvor od izuzetnog su značaja za istoriju Slovaka u Vojvodini, ali i šire za istoriju Slovaka u Južnoj Ugarskoj (Donjoj zemlji), zato što nude mnoštvo novih podataka koji se pre svega odnose na crkveni i školski život ove verske i nacionalne zajednice. U zapisnicima su i drugi podaci relevantni za društvenu istoriju koji bi u znatnoj meri mogli doprineti svestranijem osvetljenju društvenog i privrednog života Slovaka na Donjoj zemlji od kraja 18. pa sve do polovine 19. veka, u periodu koji je do sada nedovoljno istraživan. Detaljna analiza kanonskih vizitacija slovačkih evangelističkih zajednica u Sremu iz 1835. godine i u Banatu iz 1836. godine takođe bi bila svrsishodna, zato što su se do sada proučavani zapisnici pokazali kao bogat izvor podataka važnih za upotpunjenje slike o prošlosti slovačke nacionalne zajednice na teritoriji Vojvodine.

\section{Citirana literatura}

Čelovský, Samuel. „Slovenská l'udová škola v Kulpíne v období feudalizmu (17891848)", [In:] M. Krivák (ed.) Pamätnica 1789-1989, 200 rokov Základnej školy Jána Amosa Komenského v Kulpíne. Báčsky Petrovec: Kultúra, 1996.

Kollár, Ján. Čjtanka anebo kniha k Čjtánj pro mládež we sskolách slowenských w městecha w dědinách. Budín, 1825.

Lipták, Pavel. „Prehl'ad rozvoja základnej školy v Petrovci”. [In:] S. Boldocký (ed.) Petrovec 1745-1995. Báčsky Petrovec: Zhromaždenie obce, 1995, 653-667.

Maliak, Jozef. Daniel Kolényi a jeho doba. Druhé vydanie. Kulpín: Miestny odbor

rata iz 1835. godine nalazi se i zapisnik slovačke evangelističke crkvene zajednice u Staroj Pazovi (jedine tadašnje evangelističke crkvene slovačke zajednice u Sremu), a vizitirane su i nemačke evangelističke crkvene zajednice u Crvenki (Cservenka), Lovćencu (Szeghegy), Novom Vrbasu (Ujverbász), Bačkom Dobrom Polju (Kiskér), Ravnom Selu (Ujsóvé), Bačkom Jarku (Járek), Novom Sadu (Újvidék), Novoj Pazovi (Újpazua), Magliću (Bulkesz), Savinom Selu (Torzsa) i Kucuri (Kucora). 
Matice slovenskej; Báčsky Petrovec: Ú. S. tlačiareň Kultúra, 2000.

Miškovic, Samuel. Prehl'ad rozvoja školstva v Hložanoch. [In:] S. Fekete (ed.) Hložany 1756-1986. Hložany: Miestne spoločenstvo. 1986, 195-207.

Petrík, Borislav, Peter Rybár. Evanjelická encyklopédia Slovenska. Bratislava: BoPo, 2001.

Potkonjak, Nikola, Petar Šimleša (Ed.). Pedagoška enciklopedija 2. Beograd: Zavod za udžbenike i nastavna sredstva, 1989.

Rizner, Ludovít Vladimír. Bibliografia písomníctva slovenského: na spôsob slovníka od najstaršch cias do konca r. 1900. S pripojenou bibliografiou archeologickou, historickou, miestopisnou a prírodovedeckou. Diel prvý: A-F. Turčiansky Sv. Martin: Matica slovenská, 1929.

Rizner, L’udovít Vladimír. Bibliografia písomníctva slovenského: na spôsob slovníka od najstarších čias do konca r. 1900. S pripojenou bibliografiou archeologickou, historickou, miestopisnou a prírodovedeckou. Diel druhý: G-K. Turčiansky Sv. Martin: Matica slovenská, 1931.

Rizner, L’udovít Vladimír. Bibliografia písomníctva slovenského: na spôsob slovníka od najstarších čias do konca r. 1900. S pripojenou bibliografiou archeologickou, historickou, miestopisnou a prírodovedeckou. Diel tretí: L-O. Turčiansky Sv. Martin: Matica slovenská, 1932a.

Rizner, Ludovít Vladimír. Bibliografia písomníctva slovenského: na spôsob slovníka od najstarších čias do konca r. 1900. S pripojenou bibliografiou archeologickou, historickou, miestopisnou a prírodovedeckou. Diel štvrtý: P-R. Turčiansky Sv. Martin: Matica slovenská, 1932 b.

Sklabinská, Milina, Katarína Mosnáková. Slováci v Srbsku z aspektu kultúry. Nový Sad: Ústav pre kultúru vojvodinských Slovákov, 2012.

Šimoni, Ján. Dejiny školstva v Selenči. [In:] J. Gašparovský (ed.) Selenča 1758-1998. Selenča: Slovan; Báčsky Petrovec: Kultúra, 1998, 573-600.

Сеги, Ласло. Студенти са данашње територије АП Војводине на универзитетима и високим школама Краљевине Угарске 1736-1850. Нови Сад: Архив Војводине, Друштво архивских радника Војводине, 2020.

[Segi, Laslo. Studenti sa današnje teritorije AP Vojvodine na univerzitetima i visokim školama Kraljevine Ugarske 1736-1850. Novi Sad: Arhiv Vojvodine, Društvo arhivskih radnika Vojvodine, 2020.]

\section{Izvori}

Arhivska građa:

Arhiv Vojvodine u Novom Sadu, fond: Bač-bodroška županija (AV BBŽ 1794-1800).

Evangélikus Országos Levéltár: Protocolla Visitationis Ecclesiarum Eglican A. C. Bacs-Sirmiesnium, institutae anno 1835., mensibus Septembri et Octobri (Evangelistički nacionalni arhiv u Budimpešti: Protokoli kanonskih vizitacija evangelističkih a. v. crkvenih zajednica Bačko-sremskog seniorata održanih u septembru i oktobru 1835. godine)

Centralni arhiv SEAVC u Srbiji sa sedištem u Staroj Pazovi: Schema Visitationis Canonicae anno 1835 per Inclytum at Venerabilem Senioratum Bács-Sirmiensem instituendae. In: Protocollum Intimatorum et Currentalium Ecclesiae A. C. Addictorum Vetero-Pazoviensis in Sirmio ab anno 1826. Volumen VIII 


\title{
Daniela Marčok
}

\section{SLOVAK EVANGELICAL SCHOOLS IN BAČKA IN THE RECORDS OF CANONICAL VISITATIONS FROM 1835}

\begin{abstract}
Summary
Soon after the immigration of a large number of Slovaks from Upper to Lower Hungary in the late $19^{\text {th }}$ century, the population of the non-Catholic denomination acquired the right to establish their own churches and schools under their auspices. The official visit of the superior, the highest church dignitary of the Evangelical Church, to a certain church community, the so-called canonical visitation, implied control over the work of a certain church community with the obligatory record keeping.

The subject of this research was the record of canonical visitations of Slovak Evangelical schools in Bačka from 1835, especially the part related to the school. The canonical visitation was performed by the superior of the Bačka-Srem Seniorate, Jan Seberinji, who visited the Evangelical Church communities in Bajša, Gložan, Kisač, Kulpin, Lalić, Petrovac, Pivnice and Selenča.

Working conditions were difficult and teachers often changed places of service, going to those church communities where they were offered a better income by contract. The teacher's salary was determined by a contract, the so-called vocator, and consisted of a fixed part in money and kind, as well as the performance of some church rites: funeral, Christmas caroling and other.

In addition to reading and writing (in Slovak and Hungarian) and arithmetic, most of the time was devoted to religious education. Apart from Kolar's textbook, no other textbooks for students were registered in the records, and no teaching aids that would be used in teaching. Teachers prepared for classes mostly from church books: catechisms, biblical history, the Gospel of the New Testament, the Chancellery, and they also used books in geography, physics, natural history and the history of Hungary.

In all schools, more or less the basic problem was irregular attendance, especially during the spring and autumn agricultural work periods. The unconscientious sending of children to school was sometimes justified by the parents due to poverty, specifically the lack of clothes for the children and the need to help with chores at home and in the fields. There were few who attended school until the age of 12 , which was a legal obligation. It is not stated that the parents paid any penalties for that.

School buildings were mostly in a run-down condition, with a lack of inventory and teaching aids, often insufficient to accommodate all school children, i.e.: students did not have a place to sit in at a school desk.

The most common objection of the canonical visitation commission refers to the duration of classes, which instead of ten months in some church communities lasted from four to five months.

Records on canonical visitations of Slovak Evangelical Church communities in Bačka, as well as in Srem and Banat from 1835 and 1836, as a primary source are of great importance for the history of Slovaks in Vojvodina, but moreover, for the history of Slovaks in Southern Hungary (Lower Country), because they offer a multitude of data that primarily relate to the church and school life of this religious and national community.
\end{abstract}

Keywords: Slovak Evangelical schools, Bačka-Srem Seniorate, canonical visitation from 1835. 